\title{
Elastic Properties of Hydrous lower mantle and D" layer minerals
}

\author{
FEIWU ZHANG ${ }^{1}$,JIAJUN JIANG
}

State Key Laboratory of Ore Deposit Geochemistry, Institute of Geochemistry, Chinese Academy of Sciences, Guiyang 550081, China

${ }^{1}$ E-mail: zhangfeiwu@vip.gyig.ac.cn

The D" layer, above the CMB. contains strong seismic anisotropy and is characterized by an anticorrelation between the shear and bulk wave velocities, seismic discontinuity, large low-shear-velocity provinces (LLSVPs) with -1 -5\% Swave velocity anomaly, and a strong topography with laterally varying thickness from 0 to over $300 \mathrm{~km}$. The discovery of the phase transition from Bridgmanite (Brg) to post-Perovskite $(\mathrm{PPv})$ at the pressure-temperature condition corresponding to the top of the D" layer has been invoked to explain the seismic anomalous features within the D" region. The effect of volatiles such as $\mathrm{H}$ on the $\mathrm{Brg}-\mathrm{PPv}$ phase transition and physical properties has not been deeply explored yet.

In this study, the incorporation mechanisms and elastic properties of hydrous Bridgmanite (Brg) and post-Perovskite $(\mathrm{PPv})$ are investigated by using first principles calculations at the lower mantle pressures. The elastic properties calculations in both ( $\mathrm{Al}, \mathrm{Fe})$-free and ( $\mathrm{Al}, \mathrm{Fe})$-bearing systems give evidences that hydrogen has less effect on the elastic wave velocities and moduli in ( $\mathrm{Al}, \mathrm{Fe})$-free and $\mathrm{Al}$-bearing system. However, the elastic wave velocities and moduli, especially the shear velocity $V_{S}$ and the shear modulus $G$, are remarkably sensitive to the presence of hydrogen in the $\mathrm{Fe}$ bearing system. The calculated shear velocity anomaly $\left(\mathbf{d} V_{S}\right)$ are $-2.9 \%$ for $\mathrm{Fe}^{3+}{ }_{\mathrm{SiH}} \mathrm{H}-\mathrm{Brg}$ and $-3.1 \%$ for $\mathrm{Fe}^{3+}{ }_{\mathrm{SiH}} \mathrm{H}-\mathrm{PPv}$, which are very close to the average anomaly value of LLSVPs. This result may imply the Ferric-bearing hydrous $\mathrm{MgSiO}_{3}$ is likely a dominated mineral in LLSVPs. Density functional perturbation theory (DFPT) and QHA calculation have also been performed to determine the P-T phase diagram for different hydrous systems. The phase transition boundary between Brg and PPv shifts to higher or lower pressures when the hydrogen atom substitutes in the $\mathrm{Mg}$ or $\mathrm{Si}$ sites in the lattice, respectively. The existence of volatiles such as hydrogen may account for the strong lateral chemical heterogeneity in lowermost mantle.

\section{Reference}

Jiang, J., \& Zhang, F. (2019). Theoretical studies on the hydrous lower mantle and $\mathrm{D}^{\prime \prime}$ layer minerals. Earth and Planetary Science Letters, 525 